\title{
O RETORNO DO MESSIAS: ELE ESTÁ DE VOLTA E O FASCISMO ETERNO
}

\author{
The return of the Messiah: Look who's back and the eternal fascism
}

\author{
Sergio Schargel Maia de Menezes \\ https://orcid.org/0000-0001-5392-693X (D) \\ Universidade de São Paulo, Programa de Pós-Graduação em Literatura \\ Brasileira, São Paulo, SP, Brasil. 05508-900 - posdlcv@usp.br
}

Resumo: Em 2012, quando a recessão democrática mundial ainda estava apenas em seu sexto ano consecutivo de acordo com os índices da Freedom House, Timur Vermes publicou o best-seller Ele está de volta. Rapidamente transformado em filme, o absurdo da sátira política de Vermes beira o kafkiano: Hitler retorna dos mortos. É tomado levianamente como um ator fascinante, por nunca quebrar seu papel, e de forma gradual ascende novamente à política. Flexionando as fronteiras entre o real da política e o real da literatura, bem como entre o humor e o horror, Ele está de volta explora, cruamente, a possibilidade do fascismo retornar e a perigosa negação do fenômeno. Esse artigo irá colocar uma base teórica sobre o conceito de fascismo - entendendo-o como conceito político genérico, portanto passível de deslocamento para além de sua manifestação original - em diálogo com a ficção de Vermes, tornando possível, no processo, perceber não apenas aparições de traços do fascismo na ficção, mas também de suas manifestações contemporâneas. Assim, espera-se contribuir para o estado da arte ao incrementar a compreensão de um conceito polissêmico, bem como alertar para o perigo de acreditar que o fascismo morreu com a morte de Hitler em 1945. Pois, como Vermes mostra, um Hitler sempre pode estar de volta.

Palavras-chave: Literatura alemã; Teoria Política; Fascismo; Hitler; Ele está de volta.

Abstract: In 2012, when the global democratic recession was still only in its sixth consecutive year according to Freedom House, Timur Vermes published the bestseller Look who's back. Quickly transformed into a film, the absurdity of Vermes' political satire borders on the Kafkaesque: Hitler returns from the dead. He is taken lightly as a fascinating actor, for never breaking his role, and gradually ascends to politics again. Flexing the boundaries between the real of politics and the real of literature, as well as between humor and horror, Look who's back, rawly explores the possibility of fascism returning and the dangerous denial of the phenomenon. This article will put a theoretical basis on the concept of fascism - understanding it as a generic political concept, therefore liable to shift beyond its original manifestation - in dialogue with Verme's novel, making it possible, in the process, to perceive not only appearances traces of fascism in fiction, but also of its contemporary manifestations. Thus, it is expected to contribute to the state of the art by increasing the understanding of a polysemic concept, as well as to alert to the danger of believing that fascism died with Hitler's death in 1945. For, as Vermes shows, a Hitler can always come back.

Keywords: German Literature; Political Theory; Fascism; Hitler; Look who's back.

\section{Introdução}

Ele está de volta, do alemão Timur Vermes, foi publicado em 2012 e adaptado para o cinema em 2015. Na história, Hitler acorda em 2012 sem lembrar de seu suicídio ou de 
seus últimos minutos, como se nada tivesse acontecido - o livro deixa implícito que ele teria sido expulso do inferno. Mas a Berlim do século XXI é muito diferente. Com a unificação, a Alemanha se tornou uma das nações mais prósperas e culturalmente plurais da Europa. Assustado com a visão dessa nova Alemanha, cheia de imigrantes, democrática e economicamente fértil, Hitler demora um pouco para se adaptar, se estabelecendo inicialmente em uma banca de jornal, na qual passa os dias lendo os periódicos para se atualizar. Todavia, seu anacronismo é justamente o que lhe dá poder: tomado por ator fantástico por nunca quebrar o seu papel vai pouco a pouco reconquistando espaço, poder e fama. Começa a participar de programas de televisão, até receber o seu próprio show. Suas piadas sobre imigrantes se tornam um fenômeno, sua popularidade cresce em todo o país, em especial após começar a se lançar em protestos por assuntos fúteis, como fezes de cachorro e multas de trânsito. Após um irônico ataque de neonazistas que o deixam hospitalizado, Hitler passa a receber convites para integrar diversos partidos. Até retornar à política. Em uma época que um partido como a Alternative für Deutschland $(A f D)$ ganha espaço na Alemanha, a discussão levantada pelo livro mostra-se bastante atual: qualquer nação, em qualquer época, pode produzir um novo Hitler. Talvez não o genocida, mas a figura extremista, tomada por Messias, calcada em um discurso de retorno ao passado mítico, ódio às minorias e conspiracionismo.

A ficção cria e modifica o real, dobrando-o a seu bel prazer. Na era da pós-verdade, onde as fronteiras entre fato e ficção são cada vez mais tênues, a literatura - e a literatura política em específico - é flexionada com a realidade, se tornando, por vezes, mais crível que o próprio real. O limite entre ambos, que nunca foi muito bem especificado, é ainda mais atenuado (SELIGMANN-SILVA, 2003). A literatura política se apropria ou se antecede ao fato, compondo cenários que muitas vezes acabam por efetivamente acontecer. Ele está de volta foi publicado dois anos antes da criação da AfD na Alemanha, um partido cujo copresidente disse publicamente que "o Nazismo não foi mais do que cocô de pássaro na história alemã” (DEUTSCH WELLE, 2018, n.p.) e que atualmente conta com 11 membros no Parlamento Europeu e 89 membros na Bundestag (2020), constituindo o terceiro maior partido na câmara alemã. O livro de Timur Vermes retrata uma Alemanha que comete os mesmos erros da década de 1930: um establishment político que ignora a força do populismo fascista, a ascensão política de Hitler explorando ressentimentos e frustrações da população, os inimigos objetivos escolhidos de forma arbitrária. Erra quem crê que um raio não cai duas vezes no mesmo lugar, e a Alemanha é um exemplo de que isso pode acontecer.

É importante notar que a ficção não é uma representação mimética absoluta do nosso real, mas sim uma construção de um real idiossincrático. Se, na nossa realidade, por enquanto, um novo Hitler ainda não surgiu na Alemanha (apesar da ascensão da $A f D$ ), na realidade de Ele está de volta, Hitler se utiliza da metodologia fascista para chegar uma vez mais ao poder, de forma bem semelhante à década de 1930. Daí a importância da literatura e da sátira política: aponta caminhos, possíveis reais e alternativas, caso determinadas 
atitudes e decisões sejam tomadas. É o mesmo com distopias: a imaginação de futuros alternativos que parecem impossíveis faz com que questionemos o presente e o futuro da realidade. Ao incutir questionamento no leitor, a literatura política, de certa forma, através de seu próprio real, pode modificar o nosso real.

\section{Uma mensagem literária sobre fascismos de ontem e hoje}

Alguns cientistas políticos, como Yascha Mounk (2019), rejeitam a ideia de que os movimentos antidemocráticos contemporâneos que se disseminaram na última década seriam um retorno do fascismo, já que entendem que eles possuem diferenças significativas, como, para destacar, o viés economicamente liberal de alguns. De fato, mesmo que nos anos recentes seja perceptível uma ascensão de nacionalismos autoritários com fortes semelhanças aos fascismos europeus das décadas de 1920 e 1930, o contexto geopolítico mundial é diferente e complexo demais para que ele reapareça exatamente da mesma forma. Primo Levi já dizia, ainda no século XX, que "cada época possui seu próprio fascismo" (LEVI apud ALBRIGHT, 2018, p. 05). Robert Paxton (2007), em Anatomia do fascismo, cirurgicamente percebe que, assim como qualquer conceito político, o fascismo absorve novas características conforme se desloca entre espaços e tempos heterogêneos, ainda que não abandone alguns de seus traços principais.

A ingenuidade de acreditar que o fascismo não possa ressurgir na contemporaneidade é o ponto focal de Ele está de volta. A ideia do enredo reforça os argumentos de Rob Riemen (2012), em O eterno retorno do fascismo, de que o fascismo é uma possibilidade em qualquer democracia de massas. Hitler ressurge como político em uma Alemanha imensamente mais plural que julgava ter aprendido as lições da guerra. Explorando ressentimentos em questões fúteis e até absurdas como multas de trânsito e cachorros, Hitler consegue gradualmente conquistar mais e mais poder. Embora cresça através de outras formas, explorando ressentimentos diferentes de sua contraparte de 1930, a metodologia que utiliza é a mesma: um gradual processo de cerceamento de liberdades que devora frustrações para engordar cada vez mais.

A mensagem de Timur Vermes é enfática: o fascismo pode ressurgir em qualquer época, um Hitler pode reaparecer em qualquer lugar. E ele cresce se alimentando dos desejos mais mesquinhos, das menores frustrações (RIEMEN, 2012). Claro que, por se tratar de uma sátira, Vermes exagera nesses pontos. Um novo Hitler não seria literalmente o mesmo, repetindo as mesmas frases ou os mesmos gestos, ao contrário, como mostra Umberto Eco (2018), um novo Hitler buscaria se afastar de Hitler.

Um argumento ingênuo bastante corrente, principalmente em veículos de comunicação do Norte como a Foreign Affairs (BERMAN, 2016) e com pesquisadores como Yascha Mounk (2019), implica que a suposta diferença entre os fascistas de 1930 e os populistas de extrema-direita de 2020 é que os fascistas supostamente desejariam terminar a democracia, enquanto os populistas desejam apenas "melhorá-la". Na melhor das hipóteses essa corrente defende que o fascismo está no horizonte, que os populistas, 
embora não fascistas, são um sinal dos tempos. Ingênua porque essa corrente incorre a um desconhecimento da história do fascismo por ignorar não apenas que qualquer fascismo é populista (PAXTON, 2007), mas, tanto mais, por ignorar que assim como Bolsonaro e Orbán, Mussolini e Hitler afirmavam que desejavam modificar a democracia, retirá-la de seu formato liberal. A democracia que afirmavam destruir era o que compreendemos por democracia liberal, mas defendiam a criação de uma democracia para a seita fascista. É revelador, assim, quando Mussolini (2006, p. 247) fala em sua doutrina, por exemplo, que o fascismo promove o oximoro "democracia autoritária"

Na ficção, o Hitler de Ele está de volta faz o mesmo: afirma que deseja mudar a democracia. Como populista, Hitler cresce ouvindo as demandas do homem comum, o homem-massa de Riemen (2012) e Ortega y Gasset (1962) ${ }^{1}$, e atacando supostas elites que teriam deturpado a democracia de suas respectivas nações. Muito da ascensão de Hitler na Alemanha de 1930 se deve ao discurso de promoção de resgate de uma democracia que teria sido deformada. Nos populistas e fascistas de 1930 e de 2020, repetese o mesmo discurso de que apenas um Messias representando a seita escolhida pode salvar uma democracia moribunda de um inimigo objetivo corrupto e onipresente, mesmo que para isso seja preciso destruir a própria democracia (STANLEY, 2018). O discurso de resgate vem primeiro, a destruição depois. Na ficção ou no real, o fascismo sempre se aproveita da democracia para envenenar, pouco a pouco, a democracia (PAXTON, 2007). Um Estado descentralizado não é garantia de que ele não possa aparecer, no máximo pode retardar o cerceamento e, caso as instituições percebam o perigo que correm a tempo, permitir uma reação eficiente antes que seja muito tarde.

Se em 1930 o fracasso da social-democracia, as frustrações com a perda da guerra anterior e o colapso econômico catapultaram o séquito fascista ao poder, o Hitler de 2012 explora desde ressentimentos fúteis a plataformas mais amplas, como as feridas não cicatrizadas da unificação. Uma reportagem publicada no jornal O Globo (MICHAHELLES, 2019) sobre os trinta anos da reunificação alemã mostrou, por exemplo, que a $A f D$ é o principal partido para um quarto dos alemães abaixo dos 30 anos na Turíngia, um dos antigos estados da República Democrática Alemã (RDA). Angela Merkel, em um discurso, afirmou que quase metade dos habitantes da antiga $R D A$ se sentem "cidadãos de segunda classe" (MICHAHELLES, 2019, n.p.). Dados colhidos pela CNN (ROBINSON, 2019) revelam que o antissemitismo está novamente em ascensão na Alemanha, para além da islamofobia e xenofobia que cresceram junto com a quantidade de imigrantes no país.

\footnotetext{
${ }^{1}$ Criado por José Ortega y Gasset (1962) em Rebelião das massas e retomado por Rob Riemen (2012) em O eterno retorno do fascismo, implica no indivíduo que, entorpecido pela cultura e mídia de massas e por seu próprio vazio, torna-se incapaz de formular um pensamento crítico e acaba sendo devorado pelo fascismo. Quando apadrinhado por um demagogo em épocas de crise, quando se amalgama o nacionalismo com o populismo, o homem-massa tende a descambar para a violência e para o fascismo (RIEMEN, 2012). Não se trata, porém, de um conceito elitista: o homem-massa pode aparecer em qualquer esfera social. Exemplos clássicos são os apoios de Heidegger ao Nazismo e de Ezra Pound ou Pareto ao fascismo, mas não só. Exemplos mais contemporâneos podem ser vistos no apoio de Renaud Camus aos Le Pen, ou da força de Alice Weidel no AfD. Além de intelectuais, ambos são exemplos de como o fascismo, mesmo que historicamente ataque minorias, também encontra apoio de algumas dessas próprias minorias perseguidas.
} 
Como sugere Hitler, esse cenário de ressentimentos é o embrião para o trabalho de um Messias Fascista (VERMES, 2014). E, para isso, é fundamental o papel do Messias em explorar o conspiracionismo paranóico e o nacionalismo.

Vermes mostra uma Alemanha que acredita ter criado anticorpos suficientes contra o fascismo, após o trauma de 1940. Nesse ponto, a adaptação cinematográfica é mais incisiva do que o livro: questionando as barreiras entre realidade e ficção, o filme coloca, de fato, um ator travestido de Hitler pelas ruas de cidades alemãs, questionando os habitantes. Surpreende a reação dos alemães, facilmente incendiados por uma pequena fagulha. O Hitler falso, propositalmente levanta questões sobre racismo, imigração e democracia, colhendo depoimentos absurdos por onde passa. Um dos entrevistados fala que “O QI dos africanos que vêm morar na Alemanha é, em média, de 40 a 50". Em outra cena, Hitler manipula para que torcedores de futebol embebidos de nacionalismo durante a Copa de 2014 espanquem outro ator. Todas essas cenas de fato aconteceram. De acordo com a produção, durante toda a gravação em apenas uma ocasião um homem questionou o ator e se mostrou indignado. Ele está de volta é kafkiano: mostra que mesmo se Hitler reaparecesse e refundasse o NSDAP, ainda assim as pessoas seriam tomadas por um fenômeno de negação, defendendo que não poderia acontecer de novo, não ali, não hoje. Até que acontece. Não sem motivo o livro encerra com Hitler dizendo "este é um bom material para trabalhar" (VERMES, 2014, p. 300), se referindo ao próprio povo alemão.

Mas um dos pontos mais interessantes de Ele está de volta é o humor, a transformação do absurdo do fascismo em riso. No livro de Vermes (2012), e principalmente na versão cinematográfica, o humor é escrachado, pastelão em certos momentos. Como uma sátira, Vermes exagera propositalmente na criação de seu real literário. Nela, o homem-massa é ainda mais homem-massa do que no real da política, ao conceder uma nova chance para Hitler. Sob o verniz de hipérbole, a sátira de Vermes permite uma crítica ao ressurgimento do fascismo no mundo. A sátira política joga com os limites entre o real e ficção, se inspirando abertamente na política do real para tratá-lo de forma propositalmente absurda. O absurdo é o coração da sátira. Pois não é absurdo que Gulliver se depare com uma raça de homens-cavalos, que Hitler reapareça vivo em 2012 ou que baratas dominem a democracia parlamentar inglesa? O humor da sátira reside no trabalho com este absurdo, no diálogo com o impossível, com aquilo que é assumidamente irreal. Ela devora, portanto, o real para cuspir uma versão propositalmente deformada e beirando o nonsense. Por certo soa insano que Hitler seja expulso do inferno e seja eleito novamente com uma plataforma de combate a multas de trânsito, assim como é absurdo o plano das baratas de McEwan (2020), em A barata, de reverter toda a base da economia e transformar consumo em trabalho. Mas não soaria insano, no início dos anos 2000, caso se falasse no ressurgimento de um nacionalismo que levou à saída do Reino Unido da União Europeia? Ou o ressurgimento do fascismo que levou a Alemanha a lidar com um partido como a AfD? A sátira política apenas absorve o insano com o qual estamos acostumados para elevá-lo de forma exponencial a uma ideia que nos parece absurda. $O$ absurdo da ficção ataca o 
absurdo do real, mudando apenas a proximidade do sujeito com o objeto.

A sátira de Vermes joga com as fronteiras entre o humor e o horror. A violência se torna tão absurda, tão desproporcional, tão estúpida, que se torna, paradoxalmente, engraçada. Daí decorre também, em parte, uma estética da destruição. Uma destruição que causa prazer constrangido no leitor. O leitor se sente culpado por esboçar um sorriso, por exemplo, ao ler na abertura de Ele está de volta a ressalva que Vermes faz de que a volta de Hitler não aconteceu de fato:

Todos os eventos, personagens e diálogos neste livro são fictícios. Qualquer semelhança com pessoas vivas e/ou suas reações, ou com empresas, organizações etc. são mera coincidência, pois em circunstâncias similares da realidade não é possível excluir totalmente outros procedimentos e comportamentos das personagens. O autor considera importante reforçar que Sigmar Gabriel [político do SPD e ex-vice-chanceler] e Renate Künast [político do Partido Verde alemão] na verdade não conversaram com Adolf Hitler (VERMES, 2014, p. 05).

Como a abertura indica e como já foi dito, ao final do livro Hitler recebe ligações e convites de políticos e partidos tradicionais da Alemanha, incluindo o ex-vice-chanceler Sigmar Gabriel (VERMES, 2014). Isso para mostrar que, quando Hitler é interpretado como vítima dos neonazistas, sua transformação política para o Fascismo do século XXI está completa. Ele pode, agora, ascender sobre qualquer partido e qualquer plataforma que desejar.

A narração em primeira pessoa causa um mal-estar. Isto porque a narrativa humaniza Hitler. Altera sua imagem - por vezes literal - de monstro sanguinário, para tratá-lo como o maior dos monstros possíveis: um ser humano comum. Pois esse é um ponto que o fascismo mostra, tanto no real quanto no literário: o Messias Fascista, o homem forte, o Sansão capaz de retornar a nação à glória é tão pequeno, mesquinho e medíocre quanto qualquer homem (RIEMEN, 2012). O monstro é humano, portanto. Vermes afasta a imagem mitológica que se criou em torno de Hitler - um esforço que Hannah Arendt (1999) buscou realizar em algumas de suas obras, em particular Eichmann em Jerusalém - como a encarnação de Lúcifer. E, no que é a maior força da sua obra, mostra que o povo alemão foi tão culpado quanto Hitler pelo Holocausto, e que nada impede que não aconteça de novo. Como mostra Rudolph Herzog (EVANS, 2013, n.p., tradução livre): “A primeira reação após a guerra foi dizer que ele era um demônio, um hipnotizador que isentava todos da culpa. O hipnotizador é o responsável". O livro de Vermes faz com que o leitor perceba cada etapa do surgimento do fascismo a partir da visão do próprio perpetrador.

Importante destacar também o exercício de metalinguagem promovido tanto no livro quanto em sua adaptação. Há um livro dentro do livro. Borrando uma vez mais as fronteiras entre real e ficção, Hitler publica, dentro do livro, um livro também chamado Ele está de volta. Vermes, portanto, trata sua obra do início ao fim como se fosse de fato um livro publicado por Hitler, como se a ficção fosse de fato a política do real. A narrativa do livro metalinguístico é idêntica e, assim como sua contraparte do real, se torna um dos mais 
vendidos e é adaptado para o cinema. Em mais um detalhe, tanto o preço do livro real quanto do livro ficcional custa 19,33 euros, em referência ao ano de ascensão do Partido Nacional-Socialista dos Trabalhadores Alemães (NSDAP).

Em um dos pontos mais simbólicos do livro, Hitler se reúne com os dirigentes do Partido Nacional-Democrático da Alemanha (NPD), partido neonazista que reabsorveu fragmentos do NSDAP após a Guerra. Os trata, porém, com desdém. Pela impossibilidade de um partido se identificar abertamente com todos os ideais nazistas, Hitler interpela seus sucessores violentamente, chamando-os de engodo, piada, uma desonra à tradição nacionalista alemã. Simpatiza, porém, com o Partido Verde, que ironicamente interpreta como real sucessor do nazismo, por suas plataformas defesa ambientalistas, o que ele confunde com nacionalismo. Mas é na mesma cena da reunião com o NPD na adaptação cinematográfica que ocorre uma das frases mais emblemáticas, quando Hitler afirma que "o Nacional-Socialismo exige um tipo de democracia que não é compatível com a democracia" (ER IST WIE DER DA, 2015). Retomando o que foi dito anteriormente, o fascismo captura e utiliza a democracia para acabar com a democracia (PAXTON, 2007). Sem, contudo, afirmar que esse desejo de ruptura, mas se apoiando no discurso de uma democracia que não seja em seu formato liberal (MUSSOLINI, 2006). Portanto, ao menos no campo do discurso, o fascismo é certamente antiliberal. Chama a atenção, nesse sentido, políticos fascistas como Viktor Orbán, na Hungria, falarem em uma "democracia iliberal”, ou Mussolini com “democracia autoritária” (MUSSOLINI, 2006, p. 247).

Em outra cena exemplar, também no filme e na mesma reunião, Hitler afirma que "quando a situação é ruim, é boa para a gente" (ER IST WIE DER DA, 2015), evidenciando o quanto o Fascismo depende de crises para crescer. Em estabilidade, não passa de uma fagulha com pouca relevância, mas, na crise, o incêndio se alastra. $O$ homem-massa passa a desejar por um Messias que o domine e possa levar a nação de volta para tempos estáveis (RIEMEN, 2012). O fragmento também aponta como o fascismo absorve a democracia para miná-la por dentro, em um processo lento de fragilização (ARENDT, 1978). Isso em parte confere um caráter de suposta normalidade que permite que sejam tratados como apenas mais um grupo populista e extremista, sobre o que Hannah Arendt comenta:

Nos primeiros anos do poder, os Nazistas desencadearam uma avalanche de leis e decretos, mas nunca se deram ao trabalho de abolir oficialmente a Constituição de Weimar; chegaram até a deixar mais ou menos intactos os serviços públicos - fato que levou muitos observadores locais e estrangeiros a esperar que o Partido mostrasse comedimento e que o novo regime caminhasse rapidamente para a normalização. (ARENDT, 1978, p. 141).

Se tratando de uma transposição do Hitler do real para o Hitler do ficcional, assim como sua contraparte, o Hitler de Vermes (2014) é um ressentido. Em mais de uma passagem ele menciona a perda da guerra, ou, ainda mais interessante, sua frustrada 
carreira artística, culpando a terceiros ${ }^{2}$. Mas, como Messias habilidoso, Hitler percebe uma vez mais que não é o único ressentido. Como o sintomático final da obra revela, quando ele afirma que "este é um bom material para trabalhar" (VERMES, 2014, p. 300), o ressentimento melancólico está disponível na Alemanha do século XXI para ser transformado em política do vazio, assim como o estava em 1933:

Sawatzki me olhava com uma espécie de veneração silenciosa, que vi pela última vez em Nuremberg, nas centenas de milhares de pessoas em quem insuflei a esperança; pessoas estas que haviam crescido em um mundo marcado pela humilhação e pelo medo do futuro, por chalatães defasados e perdedores da guerra, e que viram em mim a mão firma que as conduziria, que estavam prontas para me seguir. (VERMES, 2014, p. 128).

O papel do machismo também é presente em Ele está de volta. Assim como a versão histórica de Hitler, sua contraparte ficcional enxerga a política como um campo bélico, no qual os homens manifestam seus instintos violentos e, por isso mesmo, gloriosos. Nesse cenário, o papel da mulher seria limitado à procriação, para gerar o maior número de soldados o mais rápido possível. Recorre, para justificar essa visão, novamente ao passado mítico, utilizando Esparta ou os vikings como imagens idealizadas de sociedades bélicas e masculinas (VERMES, 2014).

Hitler incorre, portanto, a velhos clichês de gênero, como ao tratar sua secretária com condescendência, ignorando com frequência suas perguntas ou sugestões porque "as mulheres são sempre muito impulsivas quando se trata de sentimentos. É assim naturalmente. Homens são mais objetivos, não dividimos tudo em categorias ruins, não ruins e similares." (VERMES, 2014, p. 242). A exceção é feita para Bellini, vice-presidente do estúdio para o qual é contratado como ator. Ainda assim, o respeito apenas se dá porque Hitler identifica o que entende por traços masculinos de liderança e autoridade naquela mulher, "mais homem do que todos os outros idiotas ali reunidos." (VERMES, 2014, p. 68). Aqui é possível chamar a atenção para um ponto interessante tanto do fascismo na política do real, quanto em sua versão de Ele está de volta. Como herança do reacionarismo maistreano, o fascismo toma o contemporâneo por degenerado, o que explica sua utopia regressiva (PAXTON, 2007). O inimigo objetivo, o grupo desumanizado, seria o principal responsável por essa degenerescência. Mas essa degenerescência, via de regra, não é apenas moral, artística ou social, mas principalmente masculina. Como paroxismo do poder dominante, o fascismo aspira reforçar ou retomar uma utopia regressiva e para isso, enxerga a degenerescência do contemporâneo como também sendo uma degenerescência da masculinidade (PAXTON, 2007). Isto é, o contemporâneo seria contaminado não apenas racial ou socialmente, mas, tanto mais, efeminado. Frases de Mussolini como "é melhor viver um dia como um leão a cem dias como um cordeiro" ou "tempos de paz formam homens fracos" (AZEVEDO, 2020, n.p.), evidenciam o belicismo machista do fascismo. A

\footnotetext{
2 Por sinal, o documentário Arquitetura da destruição (1989) analisa, ao trabalhar com a estética nazista e a estetização da política, a relação da alta cúpula nazista com a frustração artística, expandido para além de apenas Hitler ou Goebbels. *
} 
masculinidade reside, portanto, na guerra, no sacrifício pela nação, na luta e na morte; a paz é tomada como sinônimo de feminino ou homossexualidade.

Como é necessariamente um movimento nacionalista, o desejo de regresso ao passado é pautado principalmente pela imagem do poder hegemônico daquela nação. Em uma nação patriarcal, heteronormativa e em que brancos detenham mais poder, a utopia regressiva será particularmente forte em homens brancos, por sentirem, com a crise, que sua hegemonia está sendo esvaziada. Ocorre, então, curiosa inversão: o grupo dominante passa a se sentir vitimado, passa a sentir que minorias estão dominando a nação. Como mostra Jason Stanley (2018), em uma crise, quando o homem branco sente que não consegue mais cumprir a função que a sociedade espera dele, de provedor da família, o ressentimento melancólico aflora sujeitando-se ao jugo do Messias demagogo. Stanley (2018) cita uma pesquisa que evidencia essa questão, ao comprovar que o contato de homens brancos com grandes mudanças raciais, étnicas ou de gênero - usando o exemplo da mudança de maioria branca para não branca nos Estados Unidos - tende a diminuir o apoio destes por medidas de ações afirmativas ou imigração, por exemplo.

Paradoxalmente, no fascismo, o poder hegemônico passa a se sentir explorado, dando novo sentido à máxima de que é melhor nunca ter algo do que perdê-lo. Stanley (2018) apresenta dados que mostram que $45 \%$ e $54 \%$ dos apoiadores de Trump, por exemplo, acreditam respectivamente que os brancos e os cristãos são os grupos mais perseguidos do país. Desse sentimento de vitimização decorrem teorias da conspiração desumanizadoras como os Sábios de Sião ou o Qanon, para citar algumas. Teorias desconexas da realidade, que imaginam planos em curso de dominação mundial ou nacional por minorias. Em última instância, esse tipo de narrativa legitima genocídios como o Holocausto como forma de autodefesa:

A política fascista invoca um passado mítico puro que foi tragicamente destruído. Dependendo de como a nação é definida, o passado mítico pode ser religiosamente puro, racialmente puro, culturalmente puro ou todos os itens acima. Mas há uma estrutura comum a todas as mitificações fascistas. Em todos os passados míticos fascistas, uma versão extrema da família patriarcal reina soberana por gerações. Recuando mais no tempo, o passado mítico era um tempo de glória da nação, com guerras de conquista lideradas por generais patriotas, com exércitos repletos de guerreiros leais, seus compatriotas, fisicamente aptos e cujas esposas ficavam em casa cuidando da próxima geração. No presente, esses mitos se tornam a base da identidade da nação submetida à política fascista. $\mathrm{Na}$ retórica de nacionalistas extremos, esse passado glorioso foi perdido pela humilhação provocada pelo globalismo, pelo cosmopolitismo liberal e pelo respeito por 'valores universais', como a igualdade. Esses valores, supostamente, enfraqueceram a nação diante de desafios reais e ameaçadores para sua existência [...] O fato de que as sociedades do passado raramente eram tão patriarcais, ou tão gloriosas, quanto a ideologia fascista as faz imaginar não vem ao caso. Essa história imaginária fornece provas para apoiar a imposição de hierarquia no presente, e dita como a sociedade contemporânea deve ser e agir. (STANLEY, 2018, p. 20). 
Do desejo de retorno ao passado mítico decorre uma característica interessante: o machismo. Um ponto menos evidente do que a desumanização de grupos minoritários, embora não menos interessante, é o machismo dessa metodologia de poder. Por colocar a estrutura do poder hegemônico como força motriz, a metodologia marginaliza as mulheres. Qualquer fascismo, seja literário, histórico ou contemporâneo, deseja retirar as mulheres de posições de poder e influenciá-las e deslocá-las para o âmbito familiar, limitando-as à procriação.

Se o fascismo intensifica os preconceitos e a intolerância de uma região, é óbvio que o foco da desumanização de Hitler em Ele está de volta, assim como o foi em sua versão histórica, são os judeus. Embora os árabes e negros, com o crescimento da imigração de populações asiáticas e africanas para a Alemanha na última década, também sejam desumanizados, e embora a população judia alemã em 2018 tenha metade da quantidade da população judia alemã da década de 1930, o foco da desumanização deste novo-velho Hitler ainda recai sobre os judeus. Verossímil, considerando o crescimento do antissemitismo na Alemanha contemporânea:

Na Alemanha, a polícia revelou que atos de violência motivados por ódio aos judeus aumentaram em mais de $60 \%$ no país no período de um ano. Segundo os dados, solicitados por parlamentares do partido A Esquerda, foram 62 ataques violentos em 2018, deixando 43 pessoas feridas, enquanto em 2017 haviam sido registrados 37 ataques. Já o número total de crimes relacionados a antissemitismo, não necessariamente violentos, chegou a 1.646 em 2018 - 9,4\% a mais do que no ano anterior [...] Uma pesquisa divulgada no final de 2018 pela Agência de Direitos Fundamentais da União Europeia (FRA, na sigla em inglês) - o maior levantamento já realizado sobre antissemitismo no continente - afirma que o discurso de ódio e casos de abuso estariam se tornando algo cada vez mais normal, assim como o medo entre os judeus de serem reconhecidos publicamente como tal. [...] Segundo o estudo da FRA, 90\% dos judeus entrevistados disseram sentir um aumento do antissemitismo em seus países, enquanto $30 \%$ afirmaram que já foram alvo de ofensas. Um terço das pessoas evita ir a eventos ou locais judaicos temendo por sua segurança. A mesma proporção de pessoas afirma que considera emigrar para outros países (DEUTSCHE Welle, 2019, n.p.).

Algumas páginas adiante, mais uma vez sob o jugo da fronteira invisível entre humor e horror, Hitler trava um diálogo com a copresidente da emissora em que passa a trabalhar: “- Temos que ter em mente que o tema 'judeus' não tem graça alguma. - A senhora tem absoluta razão - concordei com ela, quase aliviado. Ali estava alguém que finalmente sabia do que estava falando." (VERMES, 2014, p. 72). Hitler é incapaz de perceber que Bellini influía justamente o contrário do que ele entende, ao dizer que o tema dos judeus não é humor. Para alguém que compara judeus a ratos (VERMES, 2014) - como não recordar da história em quadrinhos Maus, de Art Spiegelman? - é impossível entender que um alemão não manifeste igualmente o seu racismo. Entretanto, a complacência de sra. Bellini pode ser entendido como uma alusão ao establishment conservador que, embora não nazista, tolerou a ascensão do NSDAP com a esperança de benefício financeiro e político, da 
mesma forma que ela o faz. ${ }^{3}$

O humor de Vermes (2014) atinge seu mais alto expoente quando o próprio Hitler é confundido por neonazistas como um "turco judeu" e espancado em conseqüência. Os turcos são, aliás, outro alvo preferencial. Embora Hitler acredite inicialmente, ainda no processo se absorver informações sobre essa nova Alemanha, que os turcos vieram para ajudar na guerra ainda em curso, logo descobre que se tratam de imigrantes e expande sua desumanização para eles. Entretanto, a Alemanha de 2012 é muito mais miscigenada e plural do que a de 1933, o que rende mais alguns momentos em que Vermes consegue transformar a desumanização e o racismo em humor ácido:

Ainda me lembro desse momento como tendo sido levemente incômodo. Por uma fração de segundo busquei em meu cérebro explicações de como uma garota alemã séria poderia ter recebido o sobrenome Özlem, tipicamente turco, mas não encontrei nenhuma, é claro. Tirei a mão do braço dela e me virei de repente para seguir meu caminho. Eu preferiria simplesmente ter deixado aquela pessoa falsa para trás de tão decepcionado que estava, de tão traído que me senti. Infelizmente, eu não sabia aonde ir. Portanto, segui-a em silêncio, mas decidi tomar mais cuidado nesses novos tempos. Esses turcos não estavam apenas no setor de limpeza, mas em todos os lugares, estranhamente onipresentes (VERMES, 2014, p. 67).

Óbvio que, na metodologia fascista de transformar a mentira em padrão de verdade, Hitler, conforme absorve informações sobre os quase 70 anos em que estivera morto, revisa a história a seu bel-prazer. Para ele, por exemplo, a recuperação econômica alemã do pósguerra não se deu pela influência do Plano Marshall e pelas medidas socioeconômicas da economia social de mercado de Adenauer, mas pela redução de 96\% (de 400 mil para 15 mil) da população judaica no país. Da mesma forma, responsabiliza os judeus pela estagnação econômica do antigo lado oriental, "que importou por décadas - no auge da idiotice - especificamente bolchevistas e suas doutrinas judaicas" (VERMES, 2014, p. 112). Importante mencionar que para Hitler judaísmo era sinônimo de marxismo. Hitler também manifesta curioso pró-sionismo, afirmando ser lógico a criação do Estado de Israel de modo que árabes e judeus se mantivessem ocupado matando uns aos outros (VERMES, 2014, p. 112).

Sobre a desumanização de minorias há mais um ponto interessante para destacar em Ele está de volta, uma cena de destaque na adaptação cinematográfica. Embora Hitler em seu programa de TV desumanize grupos minoritários por todo o tempo, e viralize na internet justamente por isso, sua reputação quase é destruída por um momento singular: quando dá um tiro em um cachorro que o irritava. Atirar em um cachorro quase o custa a simpatia

\footnotetext{
${ }^{3}$ Sempre pertinente lembrar que não há fascismo que seja conservador. O fascismo seria incompatível ao menos com a análise clássica do conservadorismo burkeano, a quem a ideia de uma revolução baseada no ideal abstrato de nação e em um retorno a um passado idealizado seria absurda. Conforme mostra Paxton (2007, p. 44), o que há entre fascismo e conservadorismo é mais uma associação desconfortável - no qual os conservadores aceitam os fascistas como uma "escolha muito difícil", uma alternativa a qualquer proposta de esquerda ou centro-esquerda, seja moderada ou radical - do que a formação de um bloco orgânico.
} 
do público, somente restaurada quando é espancado por um grupo neonazista: "Na TV tudo é possível. O público aceita quase tudo. Agora... Atirar em um cachorro. O povo alemão nunca vai perdoar isso" (ER IST WIE DER DA, 2015, n.p.). Reaparece, portanto, a crítica ácida travestida do amalgama entre humor e horror: importa menos a violência contra homens do que a violência contra animais. Em efeito contrário, o animal é humanizado, a empatia e a alteridade se estendem sobre o animal de uma forma que não atinge o homem.

O fascismo é bem consciente do poder de uma mentira transformada em verdade, provando que as fake news nada têm de novo. Como George Orwell (2009) mostrou em 1984, dois mais dois podem facilmente se tornar cinco sob o domínio do totalitarismo. Quando não totalitário, portanto sem o poder de institucionalizar a mentira, o fascismo ainda assim desloca suas forças para torná-la absoluta. Por isso o conspiracionismo paranóico caminha junto da desumanização: facilita na melancolia do ressentimento, direcionando-a para um grupo específico. Hitler admitia abertamente em Mein kampf que "para ser bem sucedida, a mentira deve ser enorme" (ARENDT, 1978, p. 199).

O nazismo certamente foi a maior expressão do que se entende por nacionalismo fascista e é inevitável, portanto, que essa presença seja considerável em Ele está de volta. O Hitler de Vermes, bem como o Hitler histórico, se considera um emissário dos céus para conduzir a nação alemã de volta à glória: "O destino é que forja nossos planos [...] Eu faço apenas o que deve ser feito para a preservação da nação nos tempos atuais e futuros" (VERMES, 2014, p. 65). Imprime, portanto, quase uma versão contemporânea do Destino Manifesto, em que se coloca como o Messias responsável pelo resgate da glória da nação.

Se Vermes humaniza Hitler ao escrever em primeira pessoa, isso não o torna menos delirante. Seu nacionalismo não se limita ao plano político, mas se alastra por todas as esferas possíveis. Coloca-se, por exemplo, contra o euro ou a noção de União Europeia (VERMES, 2014) - evocando os nacionalismos contemporâneos que se disseminam pela Europa, com o exemplo mais evidente do Brexit - e até contra o Papai Noel, que "ganhou uma importância desproporcional, sem dúvida, em virtude da infiltração cultural angloamericana" (VERMES, 2014, p. 297). Da mesma forma, fica orgulhoso com a existência da Wikipedia, que atribui a uma grande criação alemã em homenagem a um suposto antepassado viking (VERMES, 2014). Sua visão da nação alemã como pináculo do mundo se estende, por exemplo, a raças de cachorro, as quais lista em uma passagem de acordo com a mais alemã e a menos alemã. Em outra passagem, seu nacionalismo se estende para esquilos e plantas:

Nesse exemplo, pode-se também observar, de forma extraordinária, que o conflito racial não acabou desde aquela época, que ele também se estendeu fortalecido para a natureza, e isso a atual imprensa burguesa-liberal não nega. Lê-se sempre sobre os tão amados esquilos alemães de pelagem marrom-clara ameaçados pelos esquilos pretos americanos, pelas tribos de formigas africanas que migram para a Espanha, pelas não-me-toques indogermânicas que se espalham por aqui. Este último evento é claramente exemplar, as plantas arianas exigem, com toda a razão, a área de colonização a que têm direito. Não encontrei ainda essa folhagem nova, e, 
mais resistentes, as folhas do estacionamento do hotel me parecem totalmente normais, mas o aparelho de sopro também pode ser usado tranquilamente com a folhagem tradicional (VERMES, 2014, p. 85).

Bem como sua versão histórica, o Hitler ficcional utiliza, portanto, comparações com uma pseudobiologia para comprovar suas teses de superioridade racial. Esse tipo de pensamento, junto com o conspiracionismo paranóico, acaba por justificar a perseguição ao grupo desumanizado. Afinal, se disputas raciais são fruto de formações biológicas, elas são intrinsecamente naturais. A perseguição é, assim, um mecanismo de defesa, uma ação premeditada para, na mente do fascista, impedir que o mesmo seja feito com a sua seita. Dessa transposição do nacionalismo à biologia é que surge o interesse de Hitler pelo Partido Verde, já que os interpreta como guerreiros que defendem o solo alemão (VERMES, 2014). Em uma cena do filme, por exemplo, interpela uma idosa que o pergunta se ele apóia o Partido Conservador Bávaro, ao que ele responde sua preferência pelos Verdes, já que estes "protegem a natureza da nação." (ER IST WIE DER DA, 2015, aprox. 44:50 min., tradução livre) A idosa e o homem que a acompanha, respondem que "proteger a natureza é bom, é um valor cristão" (tradução livre). Partindo dessa faísca, Hitler consegue despertar o reacionarismo em seus interlocutores, sugerindo que a Alemanha no passado era superior e que os políticos a destruíram, ao que eles, embora ainda hesitem em apoiá-lo, concordam.

Mas não há dúvida que a passagem mais emblemática do nacionalismo fascista encontra-se no filme. Isto porque, como já foi dito, o filme trafega intencionalmente nas fronteiras entre o real e a ficção, contracenando atores com cidadãos comuns. Em uma das cenas mais fortes, Hitler consegue mobilizar as emoções de um grupo de torcedores durante algum jogo da Alemanha na Copa de 2014 para agredir outro ator, interpretando um anarquista, que passa pelo grupo xingando o país. O grupo de torcedores, filmados e aplaudidos por outros tantos, chama-o de traidor, forçando-o a vestir uma camisa da Alemanha. Logo na cena seguinte, outro grupo de torcedores tira uma foto com Adolf, na qual todos fazem a saudação nazista, seguidos de uma mulher dizendo "Eu amo Hitler" (tradução livre).

No livro, a disseminação desse nacionalismo e o apoio a Hitler é mais perceptível nas esferas em torno dele. A recepcionista do hotel onde mora, por exemplo, passa a recebêlo com a saudação nazista (VERMES, 2014). Em outra passagem, em um discurso à emissora pelo sucesso de seu programa, consegue fazer com que toda a equipe responda em um uníssono "Sieg Heil" (VERMES, 2014, p. 232).

Deste nacionalismo, incorre o belicismo característico do fascismo. O fascismo vive para a guerra, é absolutamente contrário à ideia de pacifismo, como Mussolini (2006) deixa claro em sua doutrina. Nesse sentido, privações são interpretadas como passos necessários à formação de homens fortes. Revisitando o contexto da perda da Guerra e o cenário de 1946, por exemplo, o Hitler de Ele está de volta afirma que a derrota:

[...] de acordo com o antigo ideal de educação espartano, a dificuldade 
inexorável culmina em crianças e povos ainda mais fortes, e um inverno de fome, queimando impiedosamente na memória de uma nação, fará de forma muito mais duradoura que no futuro ela se preocupe antes de perder outra guerra mundial (VERMES, 2014, p. 105).

Parte de sua crítica à política contemporânea alemã gira em torno da visão dos políticos como acomodados. Para Hitler, a democracia liberal e a social-democracia européia geraram homens fracos que desprezam o valor da guerra na formação. Recapitula com nostalgia o que interpreta como políticos fortes, relembrando que a República de Weimar era formada por antinacionalistas, mas, ainda assim, antinacionalistas de pulso firme. Igualmente, a esquerda sabia "como estilhaçar o crânio do adversário político com uma caneca de cerveja" (VERMES, 2014, p. 110). Uma ode, portanto, à violência, que Vermes captura com suaestética da destruição. Ao final do livro, quando Hitler começa a receber ligações e convites de diversos partidos, inclusive de partidos de esquerda, uma delas, União para Inovação e Justiça, desperta seu interesse quando dizem que "um país no qual não se podia espancar estrangeiros, obviamente também não se podia espancar alemães", ao que ele responde, gerando gargalhadas, que não gostaria de viver em um país "onde não se pudesse espancar estrangeiros." (VERMES, 2014, p. 291).

\section{Considerações finais}

Se a Alemanha, nação que desenvolveu a melancolia da perda e da culpa, país mais economicamente próspero da União Européia, sem grandes disparidades socioeconômicas, pode verificar um aumento da metodologia fascista, menos de 100 anos após a sua primeira ascensão, então de fato o fascismo pode aparecer em qualquer época e em qualquer lugar. Se, ao menos enquanto se redige este artigo, a democracia alemã se encontra sólida e sem perigos visíveis de desmoronamento, com um PIB que é mais do que o triplo da linha segura dos $\$ 14,000$ dólares per capita acima do qual nenhuma democracia morreu até hoje, o crescimento do discurso desumanizador e racista não pode ser ignorado (MOUNK, 2018). Como analisado, o fascismo devora a democracia por dentro, gradualmente, passo a passo, pena por pena e, sempre importante lembrar, democraticamente. Nada impede que a variável do PIB, embora constante desde o golpe argentino de 1975, seja falha.

Vermes mostra isso em Ele está de volta. O livro não termina com Hitler sendo novamente eleito democraticamente ou dando um golpe. Termina com Hitler percebendo que é possível trabalhar com esse racismo e crescer politicamente com ele. Em uma passagem, quando descobre a televisão, incorre ao seu tradicional conspiracionismo paranóico herdado do Protocolo dos Sábios do Sião ao relacionar a mídia com o judaísmo: "Admito que no passado eu sentira orgulho de ter precisado de um longo estudo independente para desmascarar as mentiras judaicas distorcidas da imprensa com clareza lampejante." (VERMES, 2014, p. 57). Mas, sob o sarcasmo de Vermes, mostra assombro frente a futilidade que encontra nos canais de televisão, buscando, em vão, compreender 
que conspirações judaicas poderiam se esconder atrás de programas de culinária ou reality shows.

A literatura não é, e nem pode ser, uma representação hermética do real, ou não seria literatura (SELIGMANN-SILVA, 2003). Todavia, ajuda a construí-lo e a modificá-lo e possui com ele uma relação intrínseca; a influência que o contexto do real exerce na literatura e vice-versa não deve ser ignorado. Se por um lado a ficção não é o real, por outro seria ingênuo crer que ela atua de forma absolutamente autônoma: ambos realizam uma troca comensalista contínua. Não existe sujeito absolutamente neutro, assim como não existe ficção que não possua, ao menos em determinado grau, a influência política, ideológica, filosófica ou sentimental de seu autor (SELIGMANN-SILVA, 2003).

Quando diversos políticos ainda não enxergavam no fascismo o perigo que ele trazia, inclusive Winston Churchill, literatos como Thomas Mann já percebiam o potencial destrutivo desta política (SCHARGEL, 2020). Décadas antes de Davos se tornar receptáculo de milionários, o pequeno vilarejo foi cenário de A montanha mágica, que narra, como plano de fundo, a decadência moral da Europa no entre guerras (GRUNBERG, 2020). Albert Camus (2017), em A peste, é ainda mais incisivo e prevê um fenômeno que tomaria conta do Ur-Fascismo: o da negação; bem como o perigo do fascismo retornar de formas diferentes e dissimuladas sempre que se julgar erradicado (SCHARGEL, 2020).

Em época em que cientistas políticos e jornalistas insistem no epíteto de populismo tornado grito de guerra para classificar a esquerda ou centro-esquerda e a extrema-direita como sinônimos - a obra de Vermes é essencial não apenas por seu valor estético, mas pela sobriedade em perceber que o fascismo não morreu em 1945. Mais do que uma crítica ao fascismo, trata-se de uma crítica à incapacidade de tratar o bacilo pelo seu verdadeiro nome, e as consequências que daí decorrem. Pois, como mostra Vermes, através do exagero característico da sátira, a negação da imortalidade do bacilo fascista permite que ele reapareça infinitamente, enquanto existir democracia de massas, absorvendo traços novos conforme a conveniência. Para contrariar o axioma que diz que quem desconhece a história irá repeti-la, talvez seja justamente a memória dos fascismos que atrapalhe sua identificação contemporânea.

\section{Referências}

ALBRIGHT, Madeleine. Fascismo: um alerta. Trad. de Jaime Biaggio. São Paulo: Planeta, 2018.

ARENDT, Hannah. As origens do totalitarismo: totalitarismo, o paroxismo do poder. Trad. de Roberto Raposo. Rio de Janeiro: Editora Documentário, 1978.

ARENDT, Hannah. Eichmann em Jesuralém: um relato sobre a banalidade do mal. Trad. de José Rubens Siqueira. São Paulo: Companhia das Letras, 1999.

AZEVEDO, Reinaldo. Mais uma vez, Bolsonaro usa Mussolini, o pai do fascismo, como referência. UOL, São Paulo, 01 jun. 2020. Disponível em: 
https://noticias.uol.com.br/colunas/reinaldo-azevedo/2020/06/01/mais-uma-vez-bolsonarousa-mussolini-o-pai-do-fascismo-como-referencia.htm. Acesso em: 05 dez. 2020.

BERMAN, Sheri. Populism is not fascism. But it could be a harbinger. Foreign Affairs, dez. 2016. Disponível em: https://www.foreignaffairs.com/articles/united-states/2016-1017/populism-not-fascism. Acesso em: 19 set. 2020.

CAMUS, Albert. A peste. Trad. de Valerie Rumjanek. Rio de Janeiro: Editora Record, 2017.

DEUTSCHE WELLE. Líder populista de direita minimiza impacto do Nazismo na história alemã. 02 jun. 2018. Disponível em: https://www.dw.com/pt-br//\%C3\%ADder-populista-dedireita-minimiza-impacto-do-Nazismo-na-hist\%C3\%B3ria-alem\%C3\%A3/a-44055784\#.

Acesso em: 26 set. 2020.

ECO, Umberto. O fascismo eterno. Trad. de Eliana Aguiar. Rio de Janeiro: Record, 2018.

ER IST WIE DER DA (Ele está de volta). Direção: David Wnendt. Produção: Lars Dittrich e Christopher Müller. Roteiro: Mizzi Meyer e David Wnendt. Fotografia de HannoLentz. Deutschland: Mythos, 2015. Disponível em: www.netflix.com. Acesso em: 14 jul. 2020.

EVANS, Stephan. Timur Vermes' Hitler novel: can the Führer be funny? BBC, 01 mai. 2013. Disponível em: https://www.bbc.com/culture/article/20130417-is-it-okay-to-laugh-at-hitler. Acesso em: 27 nov. 2020.

ORTEGA Y GASSET, Jose. A rebelião das massas. Trad. de Herrera Filho. São Paulo: Linográfica Editôra LTDA., 1962.

GRUNBERG, Aarnon. Warnings about Weimar Germany could turn into self-fulfilling prophecies. The Guardian, 19 fev. 2020. Disponivel em: https://www.theguardian.com/commentisfree/2020/feb/19/warnings-weimar-germanyprophecies. Acesso em: 22 dez. 2020.

MCEWAN, lan. A barata. Trad. de Jorio Dauster. São Paulo: Companhia das Letras, 2020.

MICHAHELLES, Kristina. Queda do muro, há 30 anos, turbinou Alemanha como potência europeia e mudou Berlim radicalmente. O Globo, Rio de Janeiro, 03 nov. 2019. Disponível em: https://oglobo.globo.com/mundo/queda-do-muro-ha-30-anos-turbinou-alemanhacomo-potencia-europeia-mudou-berlim-radicalmente-24057078. Acesso em: 27 nov. 2020.

MOUNK, Yascha. El pueblo contra la democracia: por qué nuestra libertad está enpeligro y cómo salvarla. Trad. De Albino Santos Mosquera. Barcelona: Espasa Libros, 2018.

MUSSOLINI, Benito. My autobiography: with "The political and social doctrine of Fascism". New York: Dover Publications, 2006.

ORWELL, George. 1984. Trad. de Heloisa Jahn e Alexandre Hubner. São Paulo: Companhia das Letras, 2009.

PALESTRA COM YASCHA MOUNK. PUC-RIO, 2019. Disponível em: http://www.com.pucrio.br/cgi/cgilua.exe/sys/start.htm?infoid=1300\&sid=24. Acesso em: 09 mai. 2019. 
PAXTON, Robert. A anatomia do fascismo. Trad. de Patrícia Zimbres e Paula Zimbres. São Paulo: Paz e Terra, 2007.

RIEMEN, Rob. O eterno retorno do fascismo. Trad. de Maria Carvalho. Lisboa: Editorial Bizâncio, 2012.

ROBINSON, Matthew. German jews warned not to wear kippahs in public following spike in anti-semitism. CNN, Atlanta, 26 mai. 2019. Disponível em: https://edition.cnn.com/2019/05/26/europe/germany-antisemitism-kippah-intl-scliger/index.html. Acesso em: 27 nov. 2020.

SCHARGEL, Sergio. "Fascism is once more at our doors, and we still refuse to see and treat it by its name": an interview with Cultural Philosopher Rob Riemen. Revista Cantareira, Niterói, $\quad$ n. 33, p. 97-107, 2020. Disponível em: https://periodicos.uff.br/cantareira/article/view/40711. Acesso em: 14 jan. 2021.

SELIGMANN-SILVA, Márcio. História, memória, literatura: o testemunho na Era das Catástrofes. Campinas: Editora da UNICAMP, 2003.

SPIEGELMAN, Art. Maus. São Paulo: Companhia das Letras, 2005.

STANLEY, Jason. Como funciona o fascismo: a política do "nós" e "eles". Trad. de Bruno Alexander. Porto Alegre: L\&PM, 2018.

UNDERGÅNGENS ARKITEKTUR (Arquitetura da destruição). Direção: Peter Cohen. Produção: Peter Cohen. Roteiro: Peter Cohen. Suécia: [s. n.], 1989. Disponível em: https://canalcurta.tv.br/series/serie.aspx?serield=442. Acesso em: 27 nov. 2020.

VERMES, Timur. Ele está de volta. Trad. de Peterso Rissati. Rio de Janeiro: Editora Intrínseca, 2014.

\section{NOTA DE AUTORIA}

Sergio Schargel (sergioschargel maia@hotmail.com) é doutorando em Letras pela USP e doutorando em Ciência Política pela UFF. Mestre em Letras pela PUC-Rio, com sua dissertação O Ur-Fascismo ontem e hoje: aparições literárias de uma metodologia de poder tendo vencido o Prêmio Abralic de melhor dissertação do biênio. Sua pesquisa e produção artística são focadas na relação entre literatura e política, tangenciando temas como teoria política, literatura política e a obra de Sylvia Serafim Thibau.

\section{Agradecimentos}

Gostaria de agradecer à minha orientadora no mestrado em Literatura, Vera Lúcia Follain, pelas incríveis contribuições a este artigo que é um desdobramento natural da dissertação. Também gostaria de agradecer aos membros da banca de defesa, Guilherme Simões Reis e Rosana Kohl Bines por fornecerem boas sugestões. Também agradecer ao meu pai, Cláudio Armando Couce de Menezes, pela revisão, comentários e pela biblioteca da qual roubei tantos livros úteis a este trabalho. Ao CNPq pelo apoio financeiro e a todo o departamento de Literatura da PUC-Rio pelo apoio institucional.

Como citar esse artigo de acordo com as normas da ABNT

SCHARGEL, Sergio. O retorno do Messias: Ele está de volta e o facismo. Anuário de Literatura, Florianópolis, v. 26, p. 01-18, 2021.

\section{Contribuição de autoria}

Não se aplica

\section{Financiamento}

Conselho Nacional de Desenvolvimento Científico e Tecnológico - CNPq. 


\section{Consentimento de uso de imagem}

Não se aplica.

\section{Aprovação de comitê de ética em pesquisa}

Não se aplica.

\section{Conflito de interesses}

Não se aplica.

\section{Licença de uso}

Os/as autores/as cedem à Revista Anuário de Literatura os direitos exclusivos de primeira publicação, com o trabalho simultaneamente licenciado sob a Licença Creative Commons Attribution (CC BY) 4.0 International. Estra licença permite que terceiros remixem, adaptem e criem a partir do trabalho publicado, atribuindo 0 devido crédito de autoria e publicação inicial neste periódico. Os autores têm autorização para assumir contratos adicionais separadamente, para distribuição não exclusiva da versão do trabalho publicada neste periódico (ex.: publicar em repositório institucional, em site pessoal, publicar uma tradução, ou como capítulo de livro), com reconhecimento de autoria e publicação inicial neste periódico.

\section{Publisher}

Universidade Federal de Santa Catarina. Programa de Pós-graduação em Literatura. Publicação no Portal de Periódicos UFSC. As ideias expressadas neste artigo são de responsabilidade de seus/suas autores/as, não representando, necessariamente, a opinião dos/as editores/as ou da universidade.

\section{Histórico}

Recebido em: 06/03/2021

Aprovado em: 01/11/2021

Publicado em: 13/12/2021 